\title{
Effect of socioeconomic status on allergic diseases and atopy in school children
}

\author{
Sevgi Sipahi ${ }^{1}$, Hikmet Tekin Nacaroğlu ${ }^{1}$, Demet Can ${ }^{1}$, İlker Günay ${ }^{1}$, Canan Şule Ünsal- \\ Karkıner ${ }^{1}$, Hacer Kamalı1 ${ }^{1}$, Ahmet Özdemir ${ }^{1}$, Türkan Günay ${ }^{2}$ \\ ${ }^{1}$ Department of Pediatric Allergy, Dr. Behcet Uz Children's Hospital, ${ }^{2}$ Department of Public Health, Dokuz Eylul University \\ School of Medicine, Izmir, Turkey. \\ E-mail: tekin212@gmail.com \\ Received: 10th January 2017, Revised: 4th May 2017-1st June 2017, Accepted: 15th June 2017
}

SUMMARY: Sipahi S, Nacaroğlu HT, Can D, Günay İ, Ünsal-Karkıner CŞ, Kamalı H, Özdemir A, Günay T. Effect of socioeconomic status on allergic diseases and atopy in school children. Turk J Pediatr 2017; 59: 670-677.

Higher family socioeconomic status (SES) has been suggested as a risk factor for allergic diseases. We investigated the effect of SES on the prevalence of allergic diseases and atopy. The study included 13-14-year-old primary school students in Kemalpaşa, Turkey. The International Study of Asthma and Allergies in Childhood phase 1 questionnaire was administered to all students to identify allergic diseases. Those identified as having allergic diseases underwent a skin prick test (SPT). Group I included students with allergic diseases and a positive SPT. Group II comprised students with allergic disease who were SPT negative. The control group was randomly selected from the students with no allergic diseases. Three weighted SES scores were calculated for each student (equally weighted, education-weighted, and social class-weighted). SES was classified as lower, middle, or upper according to the weighted SES scores. Allergic diseases were detected in 657 of the 1,373 children who participated in the study. A higher percentage of children with allergic diseases and atopy were in the lower SES group in all weighted SES analyses compared with controls (Group I: $59 \%$, 83.1\%, 67.5\%; Group II: $62.9 \%, 80 \%, 63.5 \%$; control group: $12.4 \%, 12.9 \%, 21.2 \%$ ). Significantly more children with allergic and atopic diseases (Groups I and II) were in the lower SES group compared with the control group $(\mathrm{p}<0.001)$. In contrast to the hygiene hypothesis, we found the incidence of atopic disease was higher in families with lower SES.

Key words: atopy, allergic diseases, asthma, ISAAC, socioeconomic status.

The so called "hygiene hypothesis" has been suggested to explain the increased prevalence of childhood asthma and allergic diseases in Western countries. ${ }^{1,2}$ However, the findings of large-scale epidemiological studies conducted in the United States over the past 30 years have contradicted the hygiene hypothesis ${ }^{2}$. In particular, allergic diseases were found to be highly prevalent among individuals living in urban slums, suggesting that poverty, overcrowding and poor hygienic conditions did not protect against allergic diseases. Furthermore, environmental risk factors associated with poverty in urban settings, including smoking, overcrowding, poor ventilation, inadequate heating, and humidity, were found to increase the severity of asthma and allergic diseases..$^{2-4}$ An association between socioeconomic status (SES) and the incidence of allergic diseases has been recognized; however, the precise effects of SES on disease status are controversial. To address this issue, it is necessary to conduct prevalence studies in individuals of the same age living in the same geographic region under different socioeconomic conditions. We investigated the relationship between SES and the incidence of allergic diseases and atopy in children.

Material and Methods

Patient population

The study was conducted in Kemalpaşa, İzmir, 
Turkey. The populations of the district and city were 91,276 and 59,984, respectively. The International Study of Asthma and Allergies in Childhood (ISAAC) phase I questionnaire was administered to all 13- and 14-year-old students attending the five elementary schools in the district. All of those with allergic diseases according to the ISAAC phase I questionnaire were instructed to visit the medical center to undergo a skin prick test (SPT). Of those, children with SPT-positive responses to any allergen were assigned to Group I, and those who were SPT negative were assigned to Group II. The control group (Group III) consisted of randomly selected students with no suspected allergic diseases. Students of the groups were instructed to meet at the medical center with their parents, where they were asked to complete a questionnaire to obtain information on demographic characteristics (age, gender, birth weight, maternal and paternal age, and relocations), environmental and familial risk factors (smoking habits, number of siblings living at home, family history, time of birth, whether breastfed, transition to nutritional supplements), and SES (Fig. 1). This study was approved by the local ethics committee of our hospital (2011/07-03). Written parental consent

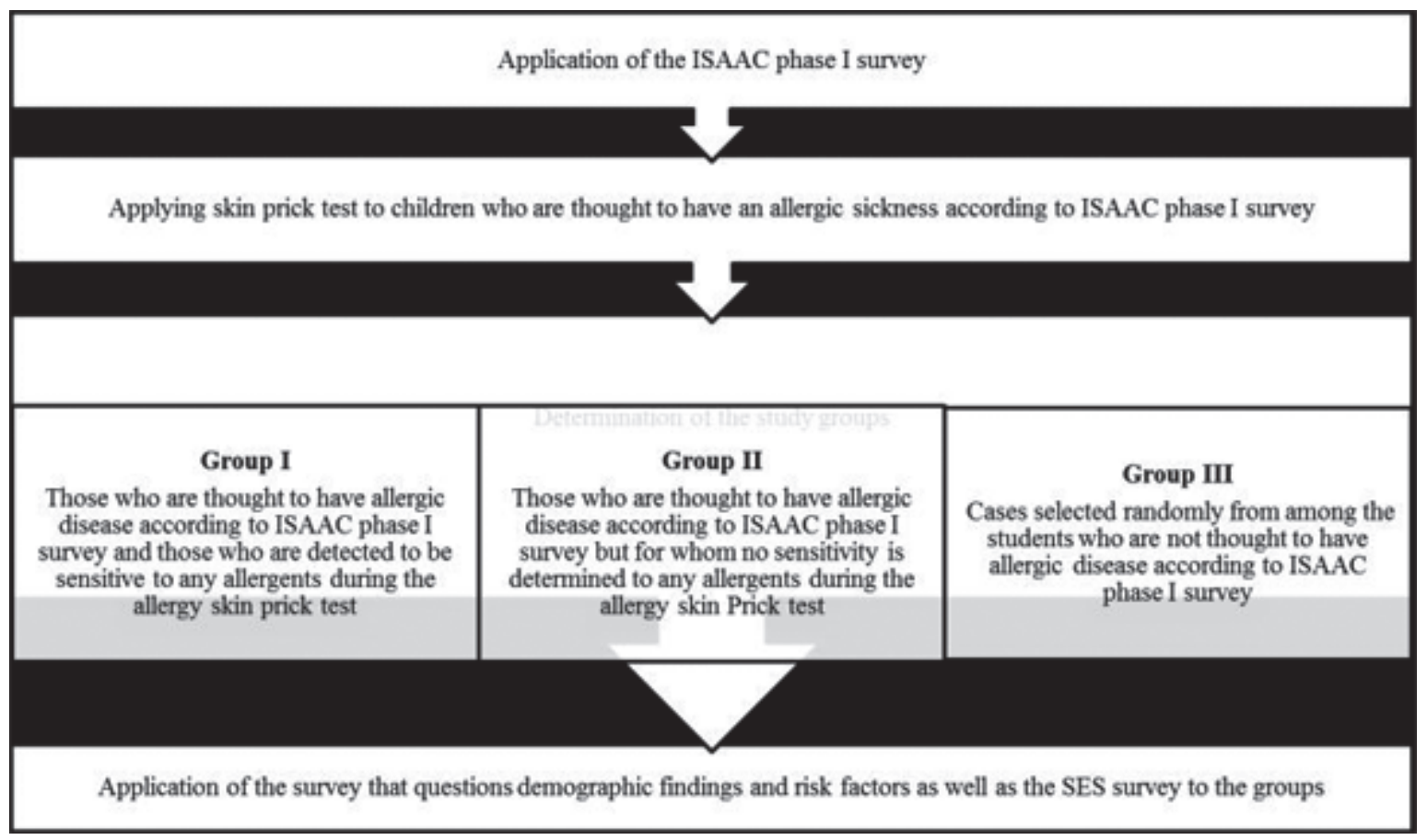

Fig. 1. Study design.

Table I. Scoring System for the Equally Weighted Socioeconomic Index.

\begin{tabular}{llc}
\hline Mother's education level & Household social class & $\begin{array}{l}\text { Equally weighted socioeconomic } \\
\text { index }{ }^{*}\end{array}$ \\
\hline Illiterate or literate but left primary school & Lower social class & 2 points \\
& Middle social class & 3 points \\
& Upper social class & 4 points \\
Primary school graduates, left secondary & Lower social class & 3 points \\
school & Middle social class & 4 points \\
& Upper social class & 5 points \\
Secondary school graduates and above & Lower social class & 4 points \\
& Middle social class & 5 points \\
& Upper social class & 6 points \\
\hline
\end{tabular}

* Lower socioeconomic group A: 2 points, Middle socioeconomic group A: 3-5 points, and Upper socioeconomic group A: 6 points. 
Table II. Scoring System for the Education-Weighted Socioeconomic Index.

\begin{tabular}{llc}
\hline Mother's education level & Household social class & $\begin{array}{l}\text { Education-weighted } \\
\text { socioeconomic index }\end{array}$ \\
\hline Illiterate or literate but left primary & Lower social class & 1 point \\
school & Middle social class & 2 points \\
& Upper social class & 3 points \\
\multirow{5}{*}{ Primary school graduates, left secondary } & Lower social class & 4 points \\
school & Middle social class & 5 points \\
& Upper social class & 6 points \\
\multirow{2}{*}{ Secondary school graduates and above } & Lower social class & 7 points \\
& Middle social class & 8 points \\
& Upper social class & 9 points \\
\hline
\end{tabular}

** Lower socioeconomic group B: 1-3 points, Middle socioeconomic group B: 4-6 points, and Upper socioeconomic group B: 7-9 points.

and student assent were obtained separately for each participant.

\section{Skin prick test}

Children were requested to discontinue antihistamine use before the SPT. SPTs for common aeroallergens (Dermatophagoides pteronyssinus, Dermatophagoides farinae), a mixture of grass pollens (Lolium perenne, Dactylis glomerata, Phleum pratense, Anthoxanthum odoratum, Poa pratensis, Festuca elatior, Agrostis vulgaris, Holcus lanatus, Cynodon dactylon, Avena sativa, Avena fatua, Lotus corniculatus), a mixture of grain pollens (oats, wheat, barley, corn), a mixture of tree pollens (Acer pseudoplatanus, Aesculus hippocastanum, Robinia pseudoacacia, Tilia platyphyllos, Platanus vulgaris), weed-mix pollens (Medicago sativa, Trifolium pratense, Brassica nigra, Urtica dioica, Rumex acetosa), Alternaria alternata, cockroaches (Blattella germanica), and cat and dog dander (Stallergenes SA, 92160 Antony, France) were performed on the anterior surface of the forearm using a Stallerpoint device (Stallergenes). Histamine $(10 \mathrm{mg} / \mathrm{ml})$ and physiological saline were used as positive and negative references, respectively. Skin reactions were evaluated $20 \mathrm{~min}$ after the skin test. A positive reaction was defined as a wheal diameter $\geq 3 \mathrm{~mm}$. Atopy was defined as at least one positive reaction to one allergen. ${ }^{5}$

\section{SES variables}

We used the socioeconomic index developed by Borotav and Belek to assess SES. ${ }^{6}$ The socioeconomic indices were calculated from information on parent education level and occupation, family social class, annual family income, and health insurance status.

Table III. Scoring System for the Social Class-Weighted Socioeconomic Index.

\begin{tabular}{|c|c|c|c|c|}
\hline \multicolumn{2}{|l|}{ Mother's education level } & \multicolumn{2}{|l|}{ Household social class } & \multirow{2}{*}{$\begin{array}{l}\text { Social class-weighted } \\
\text { socioeconomic index } \\
\text { Class }\end{array}$} \\
\hline $\begin{array}{l}\text { Education } \\
\text { Points }\end{array}$ & & $\begin{array}{l}\text { Social } \\
\text { Points } \\
\end{array}$ & & \\
\hline Illiterate & 1 & Employer & 45 & \\
\hline Literate & 2 & Highly educated, self- & 40 & 6-24 points--Lower \\
\hline Left primary school in first & 3 & employed & 35 & socioeconomic group $\mathrm{C}$ \\
\hline grade & 5 & Highly trained, paid & 30 & \\
\hline Primary school graduate & 6 & White-collar worker & 25 & 25-42 points--Middle \\
\hline Left secondary school & 8 & Small artisan/craftsman & 20 & socioeconomic group $\mathrm{C}$ \\
\hline Secondary school graduate & 9 & Blue-collar worker & 15 & \\
\hline Left high school & 11 & Unskilled service worker & 10 & 43-70 points--Upper \\
\hline High school graduate & 13 & Works whenever job & 5 & socioeconomic group $\mathrm{C}$ \\
\hline Left college & 15 & available & & . \\
\hline College graduate & & Unemployed & & \\
\hline
\end{tabular}




\section{Family social class}

Social class designation was determined by the profession of the highest earning parent. The social class categories were "upper social class" (small and middle/large employers, highly educated self-employed individuals, highly educated workers), "middle social class" (whiteand blue-collar workers and small artisans/ craftsmen), "lower social class" (unskilled service workers, workers in temporary jobs, and unemployed individuals).

\section{Socioeconomic indexes}

We performed subgroup analyses using weighted indices of the mother's education level and household social class (based on the social class of the head of the household). The equally weighted socioeconomic index used a scoring system in which the mother's education level and household social class were equally weighted (Table I). In the education-weighted socioeconomic index, the mother's education level was weighted more heavily than household social class (Table II). Social class was weighted more heavily than the mother's education level in the social class-weighted socioeconomic index (Table III). We used the socioeconomic index scores to categorize the families into lower, middle, or upper SES groups.

\section{Statistical analysis}

The Statistical Package for the Social Sciences for Windows 15.0 (SPSS, Inc., Chicago, IL, USA) was used to conduct the statistical tests. The continuous variables are expressed as the mean \pm SD or the median based on a normal distribution. Student's independent $t$-tests were used to compare normal and homogeneous distributions of parametric values. Chi-square and Mann-Whitney $U$-tests were used to compare nonparametric values. Multivariate logistic regression was used to identify significant risk factors for atopy. P-values $<0.05$ were deemed to indicate statistical significance.

\section{Results}

The study included 253 children who had allergic diseases based on the ISAAC questionnaire. Of those, 83 were SPT positive (Group I) and 170 were SPT negative (Group II). Additionally, 170 students with no allergies were randomly assigned to the control group (Group III).

\section{Gender}

Group I included 31 (37.3\%) males and 52 (62.7\%) females, Group II had 126 (74.1\%) males and $44(25.9 \%)$ females, and the control

Table IV. Characteristic and Demographic Features of the Cases.

\begin{tabular}{|c|c|c|c|}
\hline & $\begin{array}{l}\text { SPT positive } \\
\text { (Group I) }\end{array}$ & $\begin{array}{l}\text { SPT negative } \\
\text { (Group II) }\end{array}$ & $\mathrm{P}$ \\
\hline \multicolumn{4}{|l|}{ Gender } \\
\hline Male & $31(37.3 \%)$ & $70(41.2 \%)$ & \multirow[t]{2}{*}{0.55} \\
\hline Female & $52(62.7 \%)$ & $100(58.8 \%)$ & \\
\hline \multicolumn{4}{|l|}{ Number of siblings } \\
\hline 2 and below & $45(55.6 \%)$ & $105(64 \%)$ & \multirow{2}{*}{0.20} \\
\hline 3 and above & $36(44.4 \%)$ & $59(36 \%)$ & \\
\hline Breastfeeding (month) & $12.21 \pm 7.46$ & $11.55 \pm 7.44$ & 0.51 \\
\hline \multicolumn{4}{|l|}{ Passive smoking } \\
\hline Present & $51(61.4 \%)$ & $86(50.6 \%)$ & \multirow[t]{2}{*}{0.10} \\
\hline Absent & $32(38.6 \%)$ & $84(49.4 \%)$ & \\
\hline \multicolumn{4}{|l|}{ Family history of asthma } \\
\hline Present & $17(20.5 \%)$ & $12(7.1 \%)$ & \multirow{2}{*}{0.02} \\
\hline Absent & $66(79.5 \%)$ & $158(92.9 \%)$ & \\
\hline \multicolumn{4}{|c|}{ Family history of allergic rhinitis } \\
\hline Present & $30(36.1 \%)$ & $17(10 \%)$ & \multirow[b]{2}{*}{$<0.001$} \\
\hline Absent & $53(63.9 \%)$ & $153(90 \%)$ & \\
\hline \multicolumn{4}{|c|}{ Family history of atopic dermatitis } \\
\hline Present & $6(7.2 \%)$ & $9(5.3 \%)$ & \\
\hline Absent & $77(92.8 \%)$ & $161(94.7 \%)$ & 0.57 \\
\hline \multicolumn{4}{|c|}{ Timing of additional food during infancy (month) } \\
\hline
\end{tabular}




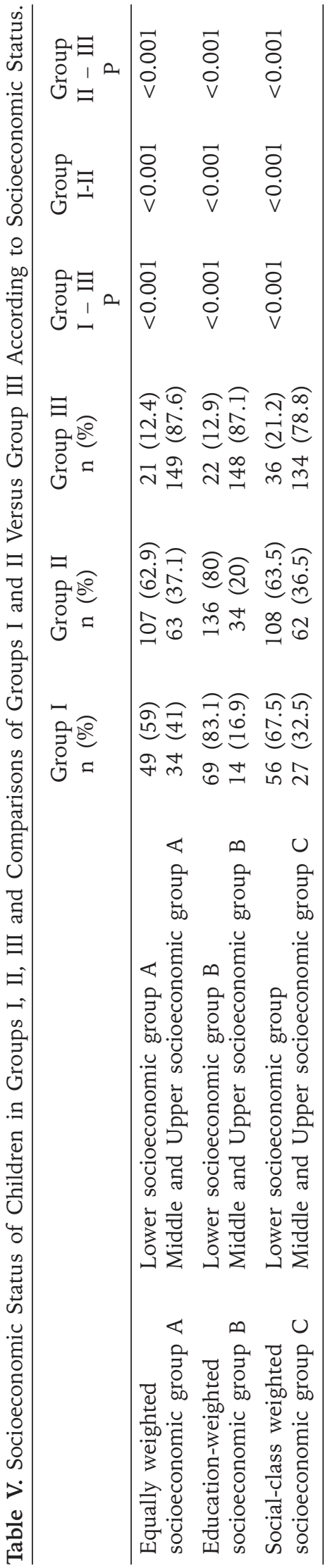

group included $70(41.2 \%)$ males and 100 $(58.8 \%)$ females. No significant gender-related differences were found between Group I and the control group; however, Group II had significantly more males than did the control group $(\mathrm{p}<0.001)$. The logistic regression analysis revealed that the likelihood of developing allergic diseases (Group I-II) in males was 4.09 times higher than that for the control group (Group III) (Odds ratio (OR): $4.09,95 \%)$

\section{Number of siblings}

The average number of siblings was two (range, 0-7 siblings). Atopy was detected in 45 children who had two siblings $(55.6 \%)$ and in 36 children who had three or more siblings $(44.4 \%)$. We did not find a significant association between the number of siblings and atopy $(\mathrm{p}=0.20)$ (Table IV).

\section{Breastfeeding}

The overall average duration of breastfeeding was 11.7 months (range, 0-48 months): 12.2 months in Group I and 11.5 months in Group II. No significant association was found between breastfeeding duration and atopy $(\mathrm{p}>0.05)$ (Table IV).

\section{Passive smoking}

In Group I, 51 (61.4\%) children were exposed to passive smoking at home compared with 32 $(17.7 \%)$ children in Group II. Passive smoking was not significantly associated with atopy ( $\mathrm{p}$ $=0.10)$. Similarly, the smoking rate of parents was not associated with the incidence of atopy in the children $(p=0.057, p=0.32$ for groups I and II, respectively) (Table IV).

\section{Family history of asthma}

A total of $17(20.5 \%)$ children in Group I had a family history of asthma compared with $12(7.1 \%)$ children in Group II. Our findings revealed that a family history of asthma significantly increased the risk of atopy in children ( $\mathrm{p}=0.02)$ (Table IV).

\section{Family history of allergic rhinitis}

In Group I, 36 (43.3\%) children had a family history of allergic rhinitis compared with $17(10 \%)$ children in Group II. We found a significant association between family history of allergic rhinitis and the risk of atopy in children ( $p<0.001)$ (Table IV). The logistic 
regression analysis revealed that the likelihood of developing allergic diseases in children with a family history of allergic rhinitis was 2.42 times higher than that of children in the control group (OR: 2.42, 95\%)

\section{Socioeconomic status}

We found that the incidence of atopic disease was significantly higher among children in the lower than in the other social class groups ( $p$ $<0.001$ ). Comparisons of Groups I and II with the control group revealed that significantly more children with allergic disease, with or without atopy, were in the lower SES group $(\mathrm{p}<0.001$ for both; Table V). Furthermore, the logistic regression analysis revealed that the likelihood of developing allergic diseases in children whose families had a lower SES was 12 times greater than that of children in the control group (OR: 12.05, 95\%).

\section{Discussion}

We investigated the relationship between social status and the incidence of allergic diseases and atopy. Contrary to the hygiene hypothesis, we found a higher incidence of allergic diseases and atopy in the children of parents of lower SES. Furthermore, the analyses of the equally weighted, social class-weighted, and educationweighted SES groups revealed that significantly more children from low SES families had atopy or allergic diseases ( $<<0.001$ ). Our study differs from previous studies in that the epidemiological conditions were optimal: all of the children in our sample were the same age and lived in the same region. Furthermore, because our study was conducted in inner-city schools in Kemalpaşa, an industrial area with several environmental risk factors for allergies and atopic disease, the setting provided an excellent laboratory for exploring several risk factors.

We used the socioeconomic index scoring system developed by Boratav to standardize SES. Boratav's study of social class in Turkey was one of the investigations to use theoretical and empirical approaches. The findings of several recent Turkish investigations of SES using Boratav's social class index, which is based on the profession of the head of the household, suggest that this index is sensitive to health indicators ${ }^{6}$. Thus, we used Boratav's socioeconomic index to assess SES.
Several studies have been conducted to clarify the relationship between bronchial asthma and socioeconomic conditions. ${ }^{6,8-14}$ Although some previous studies have found that allergic diseases were more common among families of higher SES ${ }^{6}$, others have found no association ${ }^{8}$ or have reported that allergic diseases were more common in families of lower SES. ${ }^{9-11}$ Stewart et al. ${ }^{7}$ found no association between SES and the prevalence of asthma. Persky et al. ${ }^{10}$ and Duran-Tauleria et al. ${ }^{11}$ found a negative correlation between the severity of asthma and SES. Investigations of the association between allergic diseases and SES in Turkey have yielded conflicting results. ${ }^{12,13}$ While studies conducted in Ankara, Istanbul, and Edirne found no association between SES and allergic diseases, a prevalence study conducted in Edirne, found that higher SES was a risk factor for asthma ${ }^{13}$. Talay et al. ${ }^{14}$ reported that lower SES increased the risk of asthma. These findings suggest a relationship between SES and the prevalence of allergic diseases, although the nature of the relationship is controversial. A number of factors, particularly environmental and genetic, may account for these disparate findings.

We examined the impact of SES on the incidence of allergic diseases and atopy and the demographic characteristics of children with these conditions. The logistic regression analysis revealed that the likelihood of males developing allergic disease was 4.09 times higher (Group I-II) compared with the control group. Although some studies have found that males are at higher risk of asthma before adolescence, this finding is controversial. 15,16 Overall, previous studies suggest that asthma symptoms are more common in males before puberty and in females at and after puberty; this difference is attributed to hormonal differences and gender-related differences in the development of the lungs and airways. ${ }^{16}$ Airway size is larger in girls until puberty and in males at and after puberty. ${ }^{16}$ Moreover, differences in anatomical development may contribute to variations in symptom sensitivity. ${ }^{16} \mathrm{We}$ investigated the association between the number of siblings and atopy, which we believe is associated with SES. We found that the number of siblings or people/siblings living at home was not associated with the incidence of allergic diseases with or without atopy. In a meta-analysis of studies investigating the 
relationship between family size and asthma symptoms, Karmaus and Botezan ${ }^{17}$ reported that 22 studies found that bronchial asthma symptoms decreased as family size increased and six studies found no association between the incidence of asthma and family size. Wang et al. ${ }^{18}$ conducted a study in five Canadian cities in 2003 and found no relationship between the number of people living at home and the incidence of bronchial asthma. In a study conducted in 2009 in Denizli, Turkey, Akçay et al. ${ }^{19}$ found no association between the number of people living at home and bronchial asthma.

We investigated the effect of exposure to passive smoking at home and parents' smoking rate on the development of atopic diseases. Exposure to smoking during childhood is a known risk factor for allergic diseases, particularly bronchial asthma. A study of the association between exposure to smoking and asthma in 4,331 children aged $0-5$ years found a more than 2.1-fold increased risk of asthma in children whose mothers smoked at least half a pack of cigarettes per day, and the risk was 2.6 times greater in 1-year-old children ${ }^{17}$. Kulig et al. ${ }^{20}$ reported that postnatal exposure to cigarette smoke was a risk factor for the development of wheezing in the first 3 years of life, inhibition of lung function development up to 7 years of age, and for the development of bronchial asthma after 7 years of age. We found no significant relationship between exposure to smoking at home and the incidence of atopy in children $(p=0.10)$. Furthermore, we did not find an association between atopy and the smoking rate of parents $(p=0.07, p=0.32)$. The fact that cigarette smoking is very common in Turkey may explain this negative finding.

We examined the relationship between breastfeeding duration and the incidence of atopy. Although information about breastfeeding and its duration varies among countries and regions, several studies have shown that breastfeeding is protective against the development of wheezing in early childhood. In a 2-year follow-up study, Wright et al. ${ }^{21}$ found a significant reduction in the prevalence of recurrent wheezing in children fed only breast milk for 4 or more months. However, our finding of no association between the duration of breastfeeding and atopy ( $p>0.05)$ is consistent with that of Selcuk et $a^{22}$, who found no association between breastfeeding duration and bronchial asthma or other allergic diseases in a study conducted in Edirne, Turkey. Given that most of the children with allergic diseases and atopy in our study were in the lower SES group and that lower SES is associated with lower maternal education level, we suggest that factors in addition to education contributed to the education-related differences in breastfeeding. Whether to breastfeed is a decision that all mothers must make regardless of their SES or level of education.

The etiology of atopic diseases is thought to involve a complex interaction between environmental and genetic factors, with the genetic contribution estimated to be $50-70 \%{ }^{23}$. Twin studies conducted in Denmark found that the prevalence of asthma was $4.8 \%$ in dizygotic and $19.8 \%$ in monozygotic twins, whereas an Australian study found that the prevalence was $12 \%$ in dizygotic and $30 \%$ in monozygotic twins. ${ }^{24}$ Kalyoncu et al. ${ }^{25}$ reported that a family history of atopy is the most important risk factor for all types of allergic diseases. Similarly, we found that family histories of atopy $(\mathrm{p}=$ $0.02)$ and allergic rhinitis ( $p=0.00, p<0.05)$ were significantly associated with increased risk of atopic diseases in children. However, a family history of eczema was not significantly associated with atopy ( $\mathrm{p}=0.57, \mathrm{p}<0.05)$.

In conclusion, we found that the prevalence of atopic disease was significantly higher in the children of families of lower SES. Our findings contradict the hygiene hypothesis, which postulates that atopy and allergic diseases are more prevalent in the children of families of higher SES. Kemalpaşa is in an industrial area with a large population due to frequent migration. Thus, poverty, overcrowding, and environmental risk factors such as severe air pollution, poor hygiene, smoking, poor ventilation, inadequate heating, and humidity may have increased the risk of atopic disease in our study population.

\section{REFERENCES}

1. Asher MI, Montefort S, Bjorksten B, et al. Worldwide time trends in the prevalence of symptoms of asthma, allergic rhinoconjunctivitis, and eczema in childhood: ISAAC Phases One and Three repeat multicountry cross-sectional surveys. Lancet 2006; 368: 733-743.

2. Gupta RS, Singh AM, Walkner M, et al. Hygiene factors associated with childhood food allergy and asthma. Allergy and Asthma Proc 2016; 37: 140-146. 
3. Civelek E, Cakir B, Orhan F, et al. Risk factors for current wheezing and its phenotypes among elementary school children. Pediatr Pulmonol 2011; 46: 166-174.

4. Kamalı H, Can D, Günay I, et al. The changing of prevalence of asthma among children in an industrial town. Turk J Pediatr 2014; 56: 493-499.

5. Sahiner UM, Civelek E, Yavuz ST, et al. Skin prick testing to aeroallergen extracts: what is the optimal panel in children and adolescents in Turkey? Int Arch Allergy Immunol 2012; 157: 391-398.

6. Boratav K. İstanbul ve Anadolu'dan sinıf profilleri. 2. Baskı. İstanbul: İmge Kitabevi, 2004.

7. Joyce M, Lindia J, Nevin W. Effect of economic status on the house dust mite avoidance measures in asthmatic children. Ann Allergy Asthma Immunol 1993; 71: 128-132.

8. Stewart AW, Mitchell EA, Pearce N, Strachan DP, Weiland SK. The relationship of per capita gross national product to the prevalence of symptoms of asthma and other atopic diseases in children (ISAAC). Int J Epidemiol 2001; 30: 173-179.

9. Wright AL, Holberg CJ, Taussig LM, Martinez FD. Factors influencing the relation of infant feeding to asthma and recurrent wheeze in childhood. Thorax 2001; 56: 192-197.

10. Persky V, Slezak J, Contreras A, et al. Relationships of race and socioeconomic status with prevalence, severity, and symptoms of asthma in Chicago school children. Ann Allergy Asthma Immunol 1998; 81: 266-271.

11. Duran-Tauleria E,Rona RJ. Geographical and socioeconomic variation in the prevalence of asthma symptoms in English and Scottish children. Thorax 1999; 54: 476-481.

12. Öneş Ü, Sapan N, Somer A, et al. Prevalence of childhood asthma in Istanbul, Turkey. Allergy 1997; 52: 570-575.

13. Akçakaya N. Astım. Klinik Çocuk Forumu 2003; 3: 6-13.

14. Talay F, Kurt B, Tug T, Yilmaz F, Goksugur N. Prevalence and risk factors of asthma and allergic diseases among schoolchildren in Bolu, Turkey. Acta Paediatr 2008; 97 : 459-462.
15. Çevik D, Ecevit Ç, Altınöz S, Kocabaș Ö, Kavaklı T, Öztürk A. Hişıltıll çocuklarda risk faktörleri ve etiyoloji. Toraks Dergisi 2007; 8: 149-155.

16. Yorgancıoğlu A, Kadınlarda astma ile ilgili özel durumlar. İçinde: Kalyoncu AF (ed). Bronş Astması. Ankara: Atlas Kitapç1lık, 2001: 101-103.

17. Karmaus W, Botezan C. Does a higher number of siblings protect against the development of allergy and asthma? A review. J Epidemiol Community Health 2002; 56: 209-217.

18. Wang HY, Pizzichini MM, Becker $A B$, et al Disparate geographic prevalances of asthma, allergic rhinokonjuktivitis and atopic eczema among adolescents in five Canadian cities; Pediatr Allergy Immunol 2010; 21: $867-877$.

19. Akcay A, Tamay Z, Dağdeviren E, Zencir M, Ones U, Guler N. Denizli'deki 6-7 yaş okul çocuklarında allerjik hastalıklarının prevalansları. Ege Tıp Dergisi 2007; 46: 145-150.

20. Kulig M, Luck W, Lau S, et al. Effect of pre and postnatal tabacco smoke exposure on specific sensitization to food and inhalant allergens during the first years of life. Multicenter Allergy Study Group, Germany. Allergy 1999; 54: 220-228.

21. Wright AL, Holberg CJ, Taussig LM, Martinez FD. Factors influencing the relation of infant feeding to asthma and recurrent wheeze in childhood. Thorax 2001; 56: 192-197.

22. Selcuk ZT, Caglar T, Enunlu T, Topal T. The prevalence of allergic diseases in primary school children in Edirne, Turkey. Clin Exp Allergy 1997; 27: 262-269.

23. Von Mutius E, Martinez FD. Natural history, development, and prevention of allergic disease in childhood. In: NF Adkinson Jr, JW Yunginger, WW Busse et al (eds). Middleton's allergy: principles and practice (4th ed). St. Louis, Mosby, 2003: 1169-1174.

24. Duffy DL, Martin NG, Battistutta D, Hopper JL, Mathews JD. Genetics of asthma and hay fever in Australian twins. Am Rev Respir Dis 1990; 142: 13511358.

25. Kalyoncu AF, Selcuk ZT, Karakoca Y, et al. Prevalence of childhood asthma and allergic diseases in Ankara, Turkey. Allergy 1994; 49: 485-488. 